\title{
Physical activity, obesity and cardiometabolic risk factors in 9- to 10-year-old UK children of white European, South Asian and black African-Caribbean origin: the Child Heart And health Study in England (CHASE)
}

\author{
C. G. Owen • C. M. Nightingale • A. R. Rudnicka • \\ N. Sattar • D. G. Cook $\cdot$ U. Ekelund • P. H. Whincup
}

Received: 4 January 2010 / Accepted: 7 April 2010/Published online: 9 May 2010

(C) The Author(s) 2010. This article is published with open access at Springerlink.com

\begin{abstract}
Aims/hypothesis Physical inactivity is implicated in unfavourable patterns of obesity and cardiometabolic risk in childhood. However, few studies have quantified these associations using objective physical activity measurements in children from different ethnic groups. We examined these associations in UK children of South Asian, black African-Caribbean and white European origin.

Methods This was a cross-sectional study of 2,049 primary school children in three UK cities, who had standardised anthropometric measurements, provided fasting blood samples and wore activity monitors for up to 7 days. Data were analysed using multilevel linear regression and allowing for measurement error.

Results Overall physical activity levels showed strong inverse graded associations with adiposity markers (particularly sum of skinfold thicknesses), fasting insulin, HOMA insulin resistance, triacylglycerol and C-reactive protein; for an increase of 100 counts of physical activity per min of registered time, levels of
\end{abstract}

C. G. Owen $(\bowtie) \cdot$ C. M. Nightingale $\cdot$ A. R. Rudnicka

D. G. Cook P. H. Whincup

Division of Community Health Sciences,

St George's University of London,

Cranmer Terrace,

London SW17 ORE, UK

e-mail: cowen@sgul.ac.uk

N. Sattar

British Heart Foundation Glasgow Cardiovascular Research

Centre, University of Glasgow,

Glasgow, UK

U. Ekelund

MRC Epidemiology Unit, Institute of Metabolic Science,

Addenbrooke's Hospital,

Cambridge, UK these factors were $12.2 \%$ (95\% CI 10.2-14.1\%), 10.2\% (95\% CI $7.5-12.8 \%), 10.2 \%$ (95\% CI 7.5-12.8\%), 5.8\% (95\% CI 4.0-7.5\%) and 19.2\% (95\% CI 13.9-24.2\%) lower, respectively. Similar increments in physical activity levels were associated with lower diastolic blood pressure $(1.0 \mathrm{mmHg}, 95 \% \mathrm{CI}$ $0.6-1.5 \mathrm{mmHg})$ and LDL-cholesterol $(0.04 \mathrm{mmol} / \mathrm{l}, 95 \% \mathrm{CI}$ 0.01-0.07 mmol/l), and higher HDL-cholesterol $(0.02 \mathrm{mmol} / \mathrm{l}$, 95\% CI $0.01-0.04 \mathrm{mmol} / \mathrm{l})$. Moreover, associations were broadly similar in strength in all ethnic groups. All associations between physical activity and cardiometabolic risk factors were reduced (albeit variably) after adjustment for adiposity.

Conclusions/interpretation Objectively measured physical activity correlates at least as well with obesity and cardiometabolic risk factors in South Asian and AfricanCaribbean children as in white European children, suggesting that efforts to increase activity levels in such groups would have equally beneficial effects.

Keywords Adiposity - Cardiometabolic risk - Childhood . Ethnicity $\cdot$ Physical activity
Abbreviations
ALSPAC Avon Longitudinal Study of Parents and Children
CHASE Child Heart And health Study in England
CRP C-reactive protein
EYHS European Youth Heart Study

\section{Introduction}

Low levels of physical activity in adult life increase risks of CHD, stroke, type 2 diabetes and obesity; these health 
benefits are graded across different levels of physical activity [1-4]. However, there is growing concern that physical activity levels are too low in children even in the first decade of life and that these low levels have adverse consequences for adiposity, insulin resistance, blood pressure and the metabolic syndrome [5-11].

Although earlier studies examining the effects of physical activity on health in children were based on selfreported physical activity [5, 11, 12], more recent studies have been based on objective physical activity assessment using movement sensors, which have substantially greater validity in children [13]. Substantial population-based studies using movement sensors have now related physical activity levels to adiposity, blood pressure and cardiometabolic risk during puberty in studies of 5,500 11- to 12-yearold children [6,7] and 829 15-year-olds [14]. However, data on children in the first decade of life are more limited. Although many studies of younger children have examined the associations between physical activity and adiposity [15], there is less information on the associations between physical activity and cardiometabolic factors; the largest study to date is based on 1,092 9-year-olds [14]. Moreover, information is particularly needed on the impact of objectively measured physical activity on cardiometabolic risk among children of South Asian and black AfricanCaribbean origin, who are at high risk of type 2 diabetes and cardiovascular disease in the longer term [16, 17], with an emerging global diabetes epidemic in Asian populations [18]. Thus, more information is needed to quantify the associations between objectively measured physical activity and cardiometabolic risk factors in children during the first decade of life and to assess whether these associations are similar or potentially different in different ethnic groups. The extent to which the effects of physical activity are mediated through effects on adiposity also requires further investigation.

We therefore examined the associations between objectively measured overall physical activity and a range of markers of adiposity and cardiometabolic risk (including Creactive protein [CRP], which is associated with cardiovascular and diabetes risk) $[19,20]$ in a population-based study of 2,049 children aged 9 to 10 years and of white European, South Asian and black African-Caribbean origin.

\section{Methods}

Study background The Child Heart And health Study in England (CHASE) is examining the cardiovascular health of 5,000 9- to 10-year-old children of white European, South Asian and black African-Caribbean origin living in England [21]. The investigation of physical activity and cardiometabolic risk was carried out in a sub-study of approximately 2,000 children (CHASE-2000) studied in 78 schools between February 2006 and February 2007 [22]. Ethical approval was obtained from the relevant MultiCentre Research Ethics Committee. Participating schools were identified on the basis of pupil ethnicity, using information obtained from the UK Government Department for Education and Skills. All state primary schools in London, Birmingham and Leicester that had between $15 \%$ and $50 \%$ pupils of white European origin were identified. Two separate random samples, each of 39 schools, were taken, including: (1) schools with a high prevalence (onefifth to four-fifths) of South Asian pupils, stratified by Indian, Pakistani and Bangladeshi origin; and (2) schools with a high prevalence (one-fifth to four-fifths) of black African-Caribbean pupils, stratified by African and Caribbean origin. Schools that did not agree to participate (less than one-third) were replaced by a school with similar ethnic composition and in the same borough. Invitation letters (translated where necessary) were sent to parents or guardians of pupils in year 5 classes; parental consent for the child to participate in the study was obtained. Measurements were made by a trained field team, who made fortnightly visits to different regions of London, with periodic visits to schools in Leicester and Birmingham.

Blood sampling and analysis A venous blood sample was collected from participating children between 08:30 and 10:30 hours after an overnight fast. Blood samples were separated and frozen on dry ice immediately after collection, and sent overnight to a central laboratory for analysis. $\mathrm{HbA}_{1 \mathrm{c}}$ was measured in whole blood by ion exchange high performance liquid chromatography. Serum total cholesterol, HDL-cholesterol and triacylglycerol were measured using an auto-analyser (Olympus AU-2700, Mishima, Japan), with LDL-cholesterol calculated using the Friedrickson-Friedwald equation. Plasma glucose was measured using the hexokinase method; serum insulin was measured using an ELISA method that does not cross-react with proinsulin [23]. Insulin resistance was estimated using HOMA [24]. CRP was measured by automated particleenhanced immunoturbidimetric assay (Roche, Welwyn Garden City, UK). The method has a lower limit of sensitivity of $0.1 \mathrm{mg} / \mathrm{l}$, and inter- and intra-assay coefficients of variation of $<3 \%$.

Physical measurements Height was measured using a portable stadiometer (CMS Instruments, London, UK). Weight was measured using an electronic device (Tanita, Tokyo, Japan). Ponderal index (weight $\mathrm{kg} /$ height $\mathrm{m}^{3}$ ) was used as the weight-for-height measure that is most independent of height. Leg-to-arm bioelectrical impedance was measured (Bodystat, Isle of Man, UK) and an estimate of fat mass derived using a validated equation; a fat mass 
index was derived $\left(\mathrm{kg} / \mathrm{m}^{5}\right)$ that is independent of height $(\mathrm{J}$. L. Clasey, unpublished data). Seated blood pressure was measured twice in the right arm after 5 min rest using an automated blood pressure monitor (Omron 907; Omron Healthcare, Inc., Kyoto, Japan) with an appropriately sized cuff and the average value used. Thickness of right-sided bicep, tricep, subcapsular and suprailiac skinfold thickness was combined to give the sum of skinfold thicknesses.

Physical activity assessment Children were asked to wear an activity monitor (GT1M; ActiGraph, LLC, Pensacola, FL, USA), during waking hours for seven whole days after measurement and then to return the instrument to school. The monitor, programmed to record at $5 \mathrm{~s}$ intervals, was positioned over the left hip and maintained in position with an elasticised belt. A gift voucher was issued on safe return of the monitor. On returning the instrument, children were also asked to complete a questionnaire to confirm whether they had worn the monitor every day, whether their activity level had been usual for them and whether they had been unwell at any time. They were also asked about physical activity poorly measured by the device (e.g. cycling) or requiring device removal (e.g. swimming). Downloaded ActiGraph data files were batch processed using a dedicated software program (MAHUFFE, available from www. mrc-epid.cam.ac.uk/Research/Programmes/Programme_5/ InDepth/Programme\%205_Downloads.html, accessed 20 April 2010). Activity outcomes included: mean daily activity counts, mean daily steps and activity counts per minute of registered time. Registered time was defined as the total period accepted for analysis (with time periods of at least 20 consecutive minutes of zero counts being excluded as periods of non-wear). The incomplete first and final days of recording were omitted. Only days with at least $600 \mathrm{~min}$ of recorded time were included for analysis; participants were included in the analyses if they had between 1 and 7 days of such activity recorded.

Ethnic origin and social class Determination of the ethnic origin of the child was based on parental information on the self-defined ethnicity of both parents or (where not available) parentally defined ethnicity of the child. In a small number of participants where this information was not available $(n=22)$, ethnic origin was based on information provided by the child on where parents and grandparents were born. Children of unmixed ethnic origin were classified as white European, South Asian and black African-Caribbean. Children of other ethnic origins and of mixed ethnic origin were allocated to a separate 'Other ethnic groups' category. Information on parental occupation was collected from the parents or (if not available) the child and was used to code social class using SOC-2000 classification [25].
Statistical analysis Statistical analyses were carried out using a software package (Stata/SE 10.1 for Windows; Stata LP, College Station, TX, USA). Adiposity and metabolic outcome variables were checked for normality and log-transformed where appropriate; outliers were identified and checked. Inspection of the distribution of data and the residuals from regression models showed that ponderal index, waist circumference, sum of skinfold thicknesses, fat mass index, insulin, insulin resistance, triacylglycerol and CRP required log-transformation, whereas glucose, $\mathrm{HbA}_{1 \mathrm{c}}$, LDL, HDL, and systolic and diastolic blood pressure did not. Physical activity variables (activity counts per min, activity counts) were derived using person averages from data collected on at least 1 day of measurement. Multilevel linear regression models were used to provide adjusted means for outcome variables by overall quintiles of physical activity; the assumption of linearity appeared appropriate. In addition, regression calibration [26] was used to allow for measurement error in the physical activity variable. This approach takes into account the within-child variation in physical activity across a variable number of days of recording and allows for variation in activity by day of week, to provide an unbiased average of physical activity for each child. The differences in adiposity and cardiometabolic markers (percentage change for log-transformed outcomes, in units of measure for normally distributed outcomes) per 100 increase in activity counts per minute are presented. The $z$ score (defined as the outcome variable divided by its SD) was used to assess the impact of physical activity on different outcome variables on a standardised scale. Again, the results are presented per difference of 100 in activity counts per minute. We explored whether the associations between physical activity and outcome variables differed by sex or ethnic groups using tests for interaction. All analyses were adjusted for age in quartiles, sex, ethnicity, month, observer (physical measurements and blood pressure only) and a random effect for school (to allow for clustering of children within school).

\section{Results}

The overall participation rate in the CHASE-2000 study was $69 \%$; participation rates were slightly higher among South Asians (73\%) and 'Other ethnic groups' (71\%) than among white Europeans (70\%) and black AfricanCaribbean children $(66 \%)$. Two children with an existing diagnosis of type 1 diabetes (one South Asian, one white European) were excluded. Among study participants, 2,049 (86\%) children (979 boys, 1,070 girls) successfully provided Actigraph data; of these, 1,812 children provided a 
fasting blood sample. Mean age (9.9, SD 0.4 years) was similar in boys and girls, and across ethnic groups. Physical activity data were provided for at least 5 days by 1,385 $(68 \%)$ and for 1 to 4 days by 664 (32\%); levels of activity were slightly higher in those with fewer days of physical activity data, but exclusion of these children made no material difference to the results. The demographic, ethnic and anthropometric characteristics of study participants who wore or did not wear an Actigraph were similar. Table 1 summarises adiposity and cardiometabolic markers in boys and girls, as well as physical activity outcomes (including activity counts per min and activity counts). Markers of adiposity were higher in girls than boys. In particular, sum of skinfold thicknesses and fat mass index, fasting insulin, insulin resistance, triacylglycerol and CRP were higher in girls, while fasting glucose and HDLcholesterol levels were higher in boys. Levels of physical activity (activity counts per min, total activity counts and steps) were higher in boys than girls. Due to marked sex differences in physical activity, adiposity and cardiometabolic markers, associations between these were examined separately for boys and girls. The associations of activity counts per min (quintiles) with adiposity and cardiometabolic markers are shown in Figs 1 and 2; the differences in each marker per 100 increase in activity counts per min are shown in Table 2 for boys and girls separately, and combined; combined differences are also shown as $z$ scores. Graded inverse associations were found between levels of physical activity and markers of adiposity, fasting insulin, insulin resistance, triacylglycerol, CRP, LDL-cholesterol and diastolic blood pressure; a graded positive association was apparent for HDL-cholesterol. $\mathrm{HbA}_{1 \mathrm{c}}$ and glucose concentrations showed weaker inverse associations. Associations were generally similar among boys and girls. Expressed as $z$ scores, associations between physical activity and adiposity measures (especially sum of skinfold thicknesses) were particularly strong, with a one SD increase in activity counts per min associated with a decline of about one-quarter of a SD in adiposity outcome. The corresponding declines in cardiometabolic risk factors were approximately one-sixth of a SD for insulin, insulin resistance, triacylglycerol and CRP.

Adjustment for sum of skinfold thicknesses reduced the strength of associations between physical activity and cardiometabolic markers (Table 2). Associations between physical activity, insulin and insulin resistance were reduced by a third and that between triacylglycerol and diastolic blood pressure by a half, although they remained statistically significant. Associations between physical activity, LDL- and HDL-cholesterol, and CRP were markedly reduced by adjustment for sum of skinfold thicknesses and were no longer statistically significant. These results were not materially affected by additional adjustment for other adiposity measures. The associations between physical activity, adiposity and cardiometabolic markers were similar among white Europeans, South
Table 1 Summary of adiposity, metabolic and physical activity variables by sex

Values are: ${ }^{\mathrm{a}}$ geometric mean and interquartile range (IQR) or ${ }^{\mathrm{b}}$ mean (SD), unadjusted; participants $n=$ 2,049 for anthropometry, blood pressure and physical activity variables, $n=1,853$ for CRP and $n=$ 1,812 for blood analytes

Sex differences were adjusted for age in quartiles, ethnicity, month, observer (physical measurements and $\mathrm{BP}$ ) and random effect for school

${ }^{\mathrm{c}}$ For sex difference

MVPA, moderate to vigorous physical activity; PA, physical activity

\begin{tabular}{lccc}
\hline Variable & Boys $(n=979)^{\mathrm{a}, \mathrm{b}}$ & Girls $(n=1,070)^{\mathrm{a}, \mathrm{b}}$ & $p$ value $^{\mathrm{c}}$ \\
\hline Ponderal index $\left(\mathrm{kg} / \mathrm{m}^{3}\right)$ & $13.08(2.82)^{\mathrm{a}}$ & $13.23(3.21)^{\mathrm{a}}$ & 0.16 \\
Waist circumference $(\mathrm{cm})$ & $63.7(12.7)^{\mathrm{a}}$ & $64.3(13.2)^{\mathrm{a}}$ & 0.12 \\
Sum of skinfold thicknesses $(\mathrm{mm})$ & $37.1(32.8)^{\mathrm{a}}$ & $45.4(36.0)^{\mathrm{a}}$ & $<0.0001$ \\
Fat mass index $\left(\mathrm{kg} / \mathrm{m}^{5}\right)$ & $1.78(1.16)^{\mathrm{a}}$ & $1.99(1.28)^{\mathrm{a}}$ & $<0.0001$ \\
Insulin (pmol/l) & $44.19(34.03)^{\mathrm{a}}$ & $55.53(40.28)^{\mathrm{a}}$ & $<0.0001$ \\
Insulin resistance & $0.80(0.70)^{\mathrm{a}}$ & $1.00(0.80)^{\mathrm{a}}$ & $<0.0001$ \\
Triacylglycerol (mmol/l) & $0.79(0.40)^{\mathrm{a}}$ & $0.88(0.40)^{\mathrm{a}}$ & $<0.0001$ \\
C reactive protein (mg/l) & $0.45(0.79)^{\mathrm{a}}$ & $0.63(1.26)^{\mathrm{a}}$ & $<0.0001$ \\
Glucose (mmol/l) & $4.49(0.32)^{\mathrm{b}}$ & $4.44(0.33)^{\mathrm{b}}$ & $<0.001$ \\
HbA ${ }_{1 \mathrm{c}}(\%)$ & $5.26(0.33)^{\mathrm{b}}$ & $5.27(0.32)^{\mathrm{b}}$ & 0.47 \\
LDL-cholesterol (mmol/l) & $2.63(0.67)^{\mathrm{b}}$ & $2.64(0.64)^{\mathrm{b}}$ & 0.83 \\
HDL-cholesterol (mmol/l) & $1.6(0.3)^{\mathrm{b}}$ & $1.5(0.3)^{\mathrm{b}}$ & $<0.0001$ \\
Systolic BP (mmHg) & $104.9(10.7)^{\mathrm{b}}$ & $104.1(10.7)^{\mathrm{b}}$ & 0.09 \\
Diastolic BP (mmHg) & $62.9(9.5)^{\mathrm{b}}$ & $63.0(9.3)^{\mathrm{b}}$ & 0.71 \\
Counts per min & $523.5(105.0)^{\mathrm{b}}$ & $441.2(91.6)^{\mathrm{b}}$ & $<0.0001$ \\
Counts & $431,648(82,741)^{\mathrm{b}}$ & $358,657(70,522)^{\mathrm{b}}$ & $<0.0001$ \\
Registered time (min) & $833.6(85.3)^{\mathrm{b}}$ & $820.9(80.8)^{\mathrm{b}}$ & $<0.001$ \\
Time spent sedentary (min) & $575.2(87.5)^{\mathrm{b}}$ & $584.7(82.0)^{\mathrm{b}}$ & 0.01 \\
Time spent in light PA (min) & $181.4(29.8)^{\mathrm{b}}$ & $175.4(29.6)^{\mathrm{b}}$ & $<0.0001$ \\
Time spent in MVPA (min) & $77.0(19.0)^{\mathrm{b}}$ & $60.4(14.9)^{\mathrm{b}}$ & $<0.0001$ \\
Steps & $10,560(1,845)^{\mathrm{b}}$ & $9,070(1,463)^{\mathrm{b}}$ & $<0.0001$ \\
\hline
\end{tabular}


Fig. 1 Level of physical activity by adiposity measures (a) ponderal index, (b) waist circumference, (c) sum of skinfold thicknesses and (d) fat mass index. CPM, counts of activity per min; white squares, boys; black circles, girls
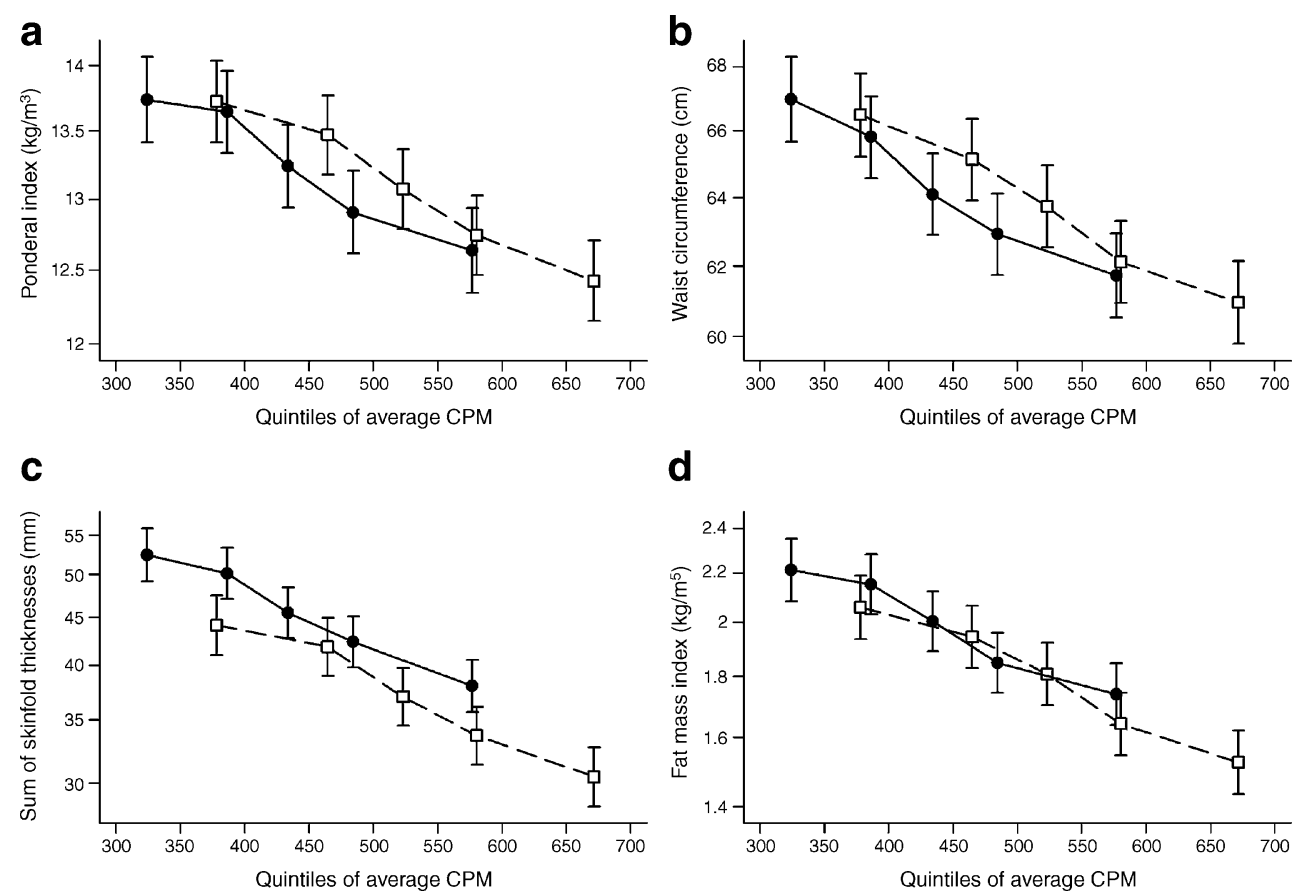

d

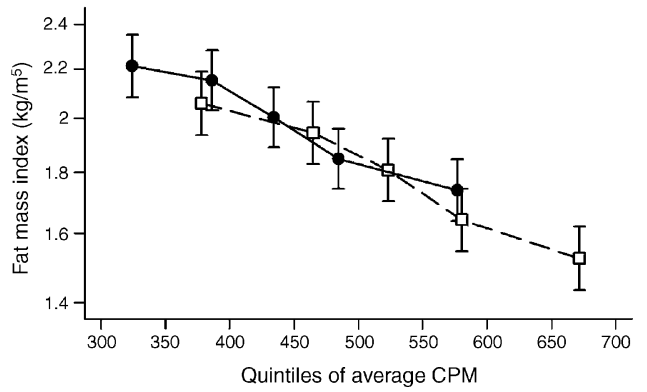

Asians, black African-Caribbeans and 'Other ethnic groups' (Table 3). Formal tests for ethnic differences in associations were not statistically significant $(p>0.1)$, except for triacylglycerol $(p=0.03)$ and HDL-cholesterol $(p=0.05)$, where effects of physical activity for the latter were stronger in ethnic minority groups, although all such associations must be treated with caution due to multiple tests. The findings presented were not affected by additional adjustment for social class or by restricting the results to the 1,385 participants who had at least 5 days of physical activity assessment. Similar patterns were seen using total activity counts and steps instead of counts per min. The findings were not materially affected by excluding the small numbers of children who reported cycling (which may not be adequately measured by accelerometry) and swimming (when the monitor was taken off).

\section{Discussion}

This study provides strong evidence that low levels of objectively measured overall physical activity are associated with increased adiposity and less favourable cardiometabolic risk profiles in childhood. The associations between physical activity, adiposity and cardiometabolic risk were graded across the range of overall physical activity and were for the most part similar in boys and girls. Moreover, we show for the first time that such associations are similar among children of different ethnic origin, including South Asian children, a group with lower levels of objectively measured physical activity [22] and high longer term diabetes risk [17, 18]. Although previous studies have related objectively measured physical activity levels to adiposity and specific cardiometabolic risk markers in children [6, 7, 14], the present study is larger and includes a wider range of risk markers than previous studies of this age-group.

The directions of association between physical activity level, obesity and cardiometabolic risk factors are broadly similar to those in previous studies using objective measures of activity [6-10, 14, 27-29]. The relationships between physical activity and adiposity measures in the present study are approximately twice as strong as those previously reported in 11- to 12-year-olds in the Avon Longitudinal Study of Parents and Children (ALSPAC) [7] and are considerably stronger than those reported for skinfold thickness in the European Youth Heart Study (EYHS) at age 9 to 10 years [10]. The modest inverse association observed between physical activity and systolic blood pressure in the present study was close to that observed in the larger ALSPAC Study in 11- to 12-year-old children [6], although the marked inverse association observed with diastolic blood pressure in the present study was considerably stronger than that observed in ALSPAC [6]. Strong inverse associations with systolic and diastolic blood pressure were observed in the EYHS among a combination of 9- to 10 - and 15- to 16-year-old children [14].

The strength of association between physical activity and insulin resistance observed in the present study is similar to that in the EYHS in combined analyses of 9- to 10- and 15to 16-year-old children [8]; we also observed a weaker association with fasting glucose [29]. The weaker association for glucose in our study may reflect the predominantly 
Fig. 2 Level of physical activity by cardiometabolic factors (a) $\mathrm{HbA}_{1 \mathrm{c}}$, (b) HOMA insulin resistance, (c) triacylglycerol, (d) LDL-cholesterol, (e) HDLcholesterol, (f) C-reactive protein, (g) systolic blood pressure and (h) diastolic blood pressure. CPM, counts of activity per min; white squares, boys; black circles, girls
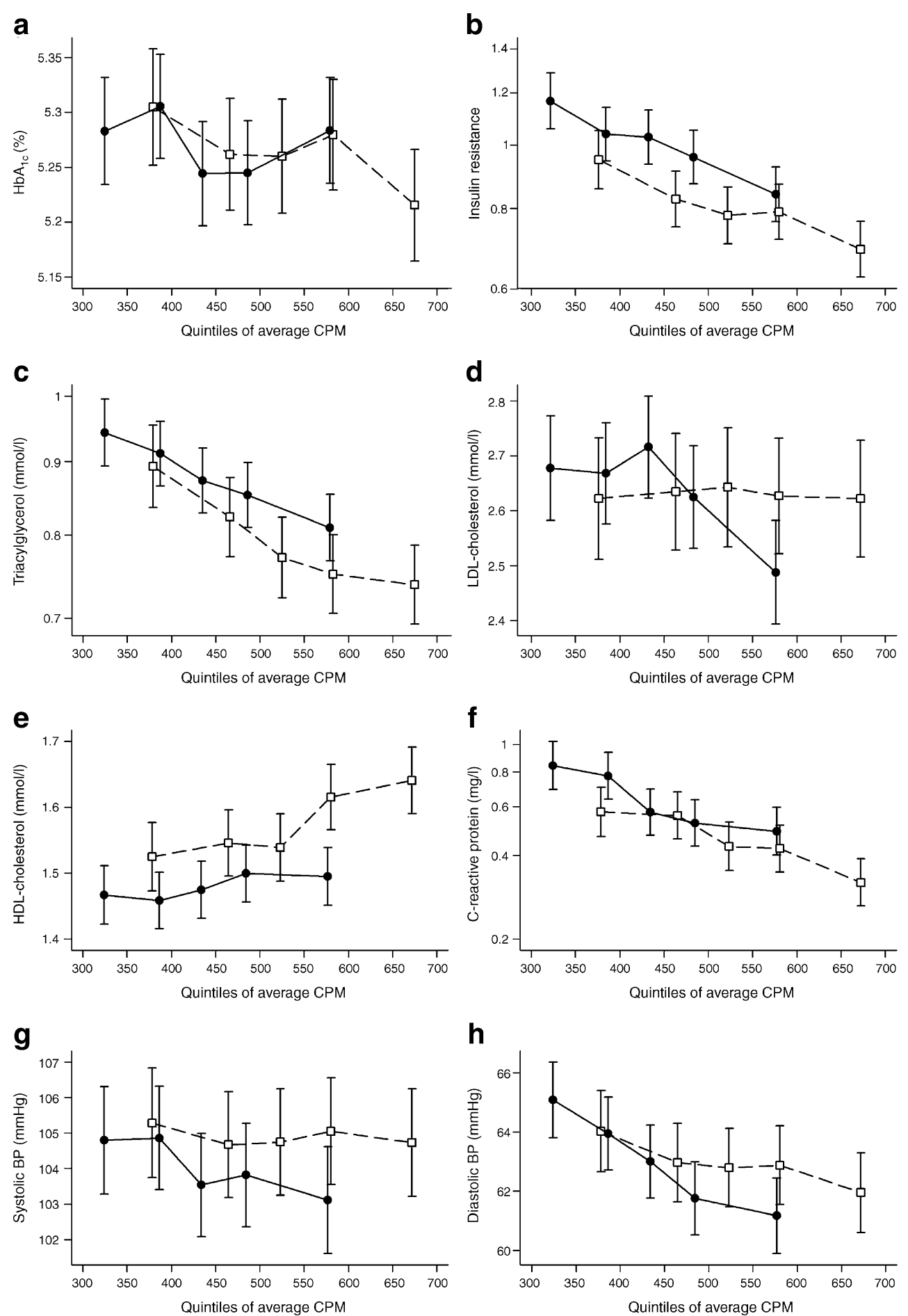

younger age group in our study, in which physical activity might plausibly affect insulin resistance without affecting glucose homeostasis to the same degree. Our observation that the association between physical activity, insulin and insulin resistance may be marginally stronger in girls than in boys is consistent with findings reported specifically for 9-year-olds studied in the Danish component of the EYHS [29].
There is little published information on the association between directly measured physical activity and CRP, a circulating marker of inflammation that is strongly linked to type 2 diabetes and cardiovascular disease in later life [19, 20]. Previous investigations using self- or parentally reported physical activity in children have suggested either a weak inverse association [30] or no association [31, 32]. The present study, markedly larger than previous 


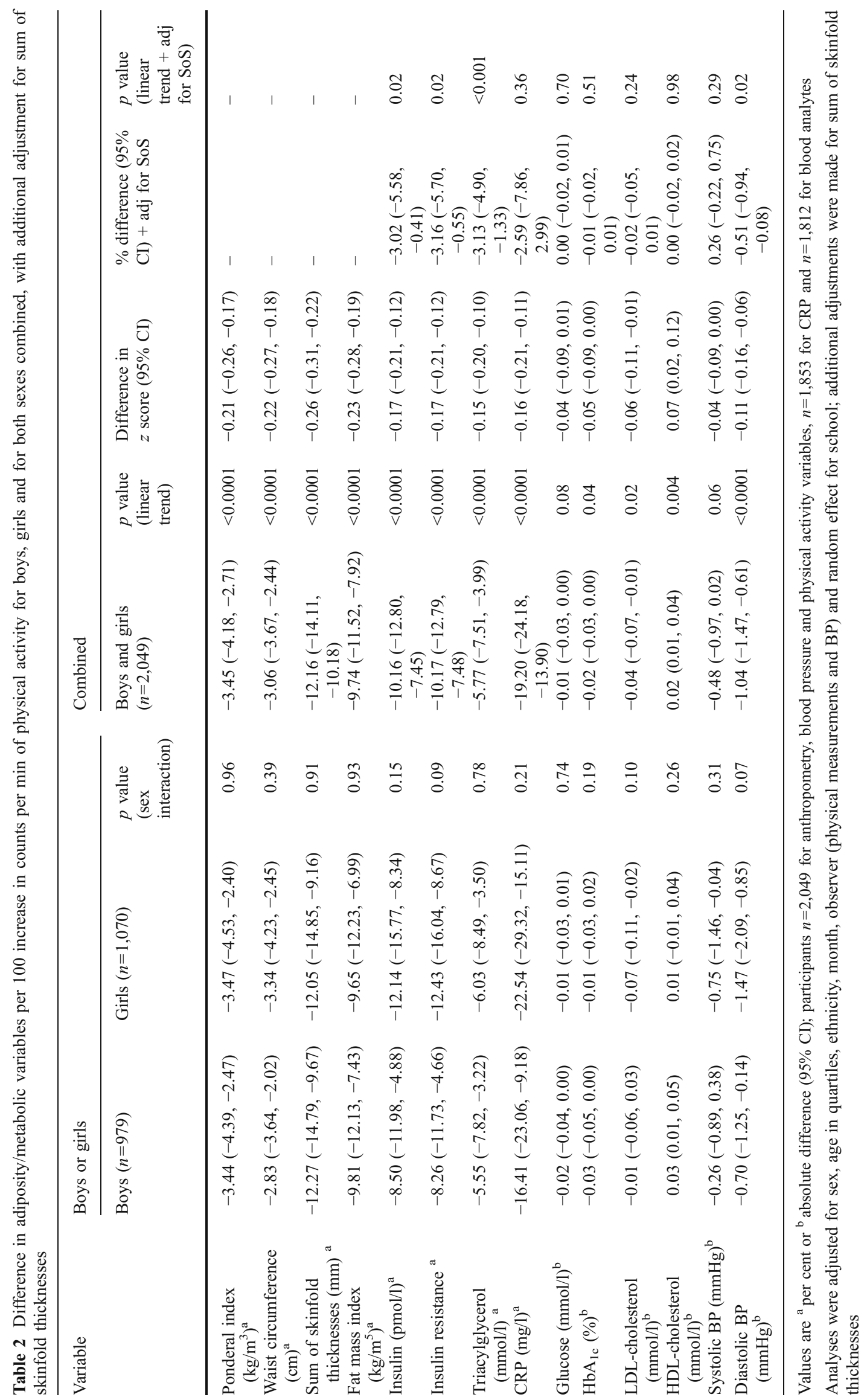


Table 3 Differences in adiposity and metabolic variables per 100 counts per min increase in physical activity by ethnic group

\begin{tabular}{|c|c|c|c|c|c|}
\hline Variable & $\begin{array}{l}\text { White European } \\
(n=499)\end{array}$ & $\begin{array}{l}\text { South Asian } \\
(n=484)\end{array}$ & $\begin{array}{l}\text { Black African- } \\
\text { Caribbean }(n=571)\end{array}$ & Other $(n=495)$ & $\begin{array}{l}p \text { value } \\
\text { (ethnicity } \\
\text { interaction) }\end{array}$ \\
\hline $\begin{array}{l}\text { Ponderal index } \\
\left(\mathrm{kg} / \mathrm{m}^{3}\right)^{\mathrm{a}}\end{array}$ & $-3.61(-4.95,-2.25)$ & $-2.67(-4.04,-1.28)$ & $-3.68(-4.98,-2.37)$ & $-3.78(-5.11,-2.44)$ & 0.61 \\
\hline $\begin{array}{l}\text { Waist } \\
\text { circumference } \\
(\mathrm{cm})^{\mathrm{a}}\end{array}$ & $-2.75(-3.88,-1.60)$ & $-2.34(-3.48,-1.18)$ & $-3.60(-4.68,-2.50)$ & $-3.45(-4.56,-2.33)$ & 0.33 \\
\hline $\begin{array}{l}\text { Sum of skinfold } \\
\text { thicknesses }(\mathrm{mm})^{\mathrm{a}}\end{array}$ & $-11.79(-15.33,-8.11)$ & $-9.09(-12.79,-5.24)$ & $-13.87(-17.21,-10.40)$ & $-13.46(-16.89,-9.90)$ & 0.21 \\
\hline $\begin{array}{l}\text { Fat mass index } \\
\left(\mathrm{kg} / \mathrm{m}^{5}\right)^{\mathrm{a}}\end{array}$ & $-10.45(-13.67,-7.10)$ & $-6.97(-10.36,-3.45)$ & $-10.14(-13.27,-6.90)$ & $-11.13(-14.29,-7.85)$ & 0.28 \\
\hline Insulin $(\mathrm{pmol} / \mathrm{l})^{\mathrm{a}}$ & $-9.75(-14.52,-4.72)$ & $-10.13(-14.90,-5.10)$ & $-12.08(-16.58,-7.34)$ & $-8.61(-13.29,-3.67)$ & 0.77 \\
\hline Insulin resistance ${ }^{\mathrm{a}}$ & $-10.30(-15.01,-5.33)$ & $-9.79(-14.55,-4.77)$ & $-12.06(-16.54,-7.35)$ & $-8.46(-13.12,-3.55)$ & 0.75 \\
\hline $\begin{array}{l}\text { Triacylglycerol } \\
(\mathrm{mmol} / 1)^{\mathrm{a}}\end{array}$ & $-8.58(-11.65,-5.41)$ & $-5.13(-8.31,-1.85)$ & $-7.05(-10.07,-3.94)$ & $-2.32(-5.49,0.96)$ & 0.03 \\
\hline $\begin{array}{l}\mathrm{C} \text { reactive protein } \\
(\mathrm{mg} / \mathrm{l})^{\mathrm{a}}\end{array}$ & $-16.48(-25.76,-6.04)$ & $-16.86(-26.04,-6.54)$ & $-18.87(-27.49,-9.23)$ & $-24.01(-32.19,-14.85)$ & 0.61 \\
\hline Glucose $(\mathrm{mmol} / \mathrm{l})^{\mathrm{b}}$ & $-0.04(-0.07,-0.01)$ & $0.00(-0.03,0.03)$ & $-0.02(-0.05,0.01)$ & $-0.01(-0.04,0.02)$ & 0.24 \\
\hline $\mathrm{HbA}_{1 \mathrm{c}}(\%)^{\mathrm{b}}$ & $0.01(-0.02,0.04)$ & $-0.03(-0.06,0.00)$ & $-0.04(-0.06,-0.01)$ & $-0.01(-0.04,0.02)$ & 0.14 \\
\hline $\begin{array}{l}\text { LDL-cholesterol } \\
(\mathrm{mmol} / \mathrm{l})^{\mathrm{b}}\end{array}$ & $-0.06(-0.12,0.00)$ & $-0.03(-0.09,0.03)$ & $-0.01(-0.07,0.04)$ & $-0.05(-0.11,0.00)$ & 0.70 \\
\hline $\begin{array}{l}\text { HDL-cholesterol } \\
(\mathrm{mmol} / \mathrm{l})^{\mathrm{b}}\end{array}$ & $-0.01(-0.04,0.02)$ & $0.04(0.01,0.07)$ & $0.03(0.01,0.06)$ & $0.03(0.00,0.06)$ & 0.05 \\
\hline $\begin{array}{l}\text { Systolic BP } \\
(\mathrm{mmHg})^{\mathrm{b}}\end{array}$ & $-0.70(-1.59,0.20)$ & $-0.91(-1.82,0.00)$ & $-0.41(-1.28,0.45)$ & $0.07(-0.81,0.95)$ & 0.43 \\
\hline $\begin{array}{l}\text { Diastolic BP } \\
(\mathrm{mmHg})^{\mathrm{b}}\end{array}$ & $-1.37(-2.16,-0.59)$ & $-0.92(-1.72,-0.13)$ & $-1.18(-1.93,-0.42)$ & $-0.67(-1.45,0.10)$ & 0.59 \\
\hline
\end{tabular}

Values are ${ }^{\mathrm{a}}$ per cent or $^{\mathrm{b}}$ absolute differences $(95 \% \mathrm{CI})$; participants $n=2,049$ for anthropometry, blood pressure and physical activity variables, $n=1,853$ for CRP and $n=1,812$ for blood analytes

Analyses adjusted for sex, age in quartiles, ethnicity, month, observer (physical measurements and BP), interaction between ethnicity and physical activity, and random effect for school

investigations, suggests that there is a strong inverse association between objectively measured physical activity and CRP in children. This is of interest since, although the value of CRP as an independent risk factor is still much debated, high CRP levels have recently been added as a recommendation for statin therapy by the US Food and Drug Administration [33].

The present study has several strengths and weaknesses. An important strength is the use of objective assessment of physical activity by means of a movement sensor (Actigraph). The instrument provides good characterisation of overall levels of physical activity and has been validated against gold standard measures of energy expenditure [34]. The study complements earlier investigations in providing data on almost twice as many 9- to 10-year-old children as in the previous investigation including prepubertal children [10]. It includes, for the first time, a balanced representation of South Asians and black African-Caribbeans as well as white Europeans. However, testing for ethnic differences in associations between physical activity and cardiometabolic risk markers is limited given the weak statistical power of formal tests for interaction. Appropriate adjustment was made for variations in physical activity by day of week and season. Although participation rates were modest $(61 \%$ overall), these were similar to or higher than those in previous studies [6-10, 14, 27-29] and are unlikely to have affected the strengths of associations between physical activity, obesity and cardiometabolic markers. Although participants who provided a single day of physical activity data were included in the analysis, most participants (68\%) provided five or more days of physical activity and the exclusion of participants who contributed only 1 day of physical activity data made little difference to the results. An additional strength of our analysis was the use of regression calibration [26] to allow for measurement error in physical activity. Not surprisingly, we found that the coefficients for physical activity were strengthened by about $30 \%$ when allowing for measurement error in this way. This emphasises that previous estimates that have not allowed for measurement error will be underestimates of the relationships.

The cross-sectional nature of CHASE, a feature of many previous studies in children $[6-8,10,14]$, is both a strength 
and a limitation. Cross-sectional studies can yield important information about the association between physical activity and cardiometabolic risk, since physical activity patterns are reasonably stable over time in children [35] and many of the important potential effects of physical activity on cardiometabolic risk are short-term. It remains possible that a degree of reverse causality is present, whereby increased adiposity and adverse cardiometabolic risk profiles (particularly resulting from excess energy intake) contribute to reduced physical activity, possibly further increasing adiposity. This possibility can only be directly excluded by prospective study data. A recent report from ALSPAC [36] showed that higher levels of physical activity at 12 years of age are strongly associated with lower levels of fat mass 2 years later, suggesting a causal interpretation.

The associations between physical activity and insulin, blood pressure and blood lipids may be mediated partially or wholly by the effects of physical activity on adiposity. In the present study, adjustment for adiposity substantially reduced associations with insulin, blood pressure and blood lipids; the reductions in associations for insulin and blood pressure were very similar to those in earlier reports $[6,8]$, although, as with the large ALSPAC study, effects on diastolic blood pressure appeared to be at least partly independent of adiposity [6]. Some other associations (particularly those for insulin, insulin resistance and triacylglycerol, all of which are strong risk factors for diabetes) also remained statistically significant after adiposity adjustment. This suggests, in keeping with other studies [8, 29], that other biological processes, independent of absolute levels of adiposity, may explain some of the beneficial effect of increased physical activity on diabetes risk and, perhaps to a lesser extent, on CVD risk. For diabetic risk factors [29], this is consistent with intervention studies in adults showing that increasing physical activity in isolation reduces type 2 diabetes risk [37].

Assuming that the observed strengths of association between physical activity and cardiometabolic risk are causal and the effects of physical inactivity are reversible, the results of the present study suggest that increasing usual overall physical activity levels in childhood by approximately a tenth (equivalent to an increase from 500 to 550 activity counts per min or increasing daily step count from 10,000 to 11,000 ) would produce appreciable reductions in markers of adiposity ( $6 \%$ reduction in sum of skinfold thicknesses, 5\% reduction in fat mass index) and cardiometabolic risk (fasting insulin by $5 \%$, triacylglycerol by $3 \%$, CRP by $10 \%$, LDL-cholesterol by $0.02 \mathrm{mmol} / 1$ and diastolic blood pressure by approximately $0.5 \mathrm{mmHg}$ ). These effects (which would be expected to be broadly similar in girls and boys, and in different ethnic groups) would be of considerable importance in public health terms. As well as addressing the short-term impacts, particularly of obesity [38], the tracking of physical activity, adiposity, insulin resistance and cardiovascular risk markers between childhood and adult life [39] suggests that increasing overall physical activity levels from childhood may translate into longer term health benefits such as reducing the burden of chronic disease in later life.

We found that the associations between physical activity, adiposity and cardiometabolic markers in South Asians and black African-Caribbeans are mostly similar in direction and strength to those in white Europeans. This is important in the context of the high adult risks of obesity and type 2 diabetes in South Asians and black African-Caribbeans [16-18], as well as in connection with our previous findings in South Asian children that physical activity levels are low [22] and cardiometabolic risk high, with higher levels of adiposity, insulin resistance and triacylglycerol levels, and low HDLcholesterol [21]. The present results suggest that the cardiometabolic benefits of increasing physical activity levels are likely to be just as marked in South Asians (and black African-Caribbeans) as in white Europeans, so that a given increase in physical activity level might be expected to have similar cardiometabolic effects in different ethnic groups. However, the scope for increasing physical activity levels is likely to be particularly marked among South Asians, given their particularly low physical activity levels.

The optimal approaches to achieving increases in physical activity, as well as the question of whether optimal cardiometabolic benefits will be achieved by focusing on overall levels of activity or by increasing amounts of time in moderate and vigorous activity remain unclear [40]. To date, practical efforts to reduce levels of overweight [41] and to increase overall levels of physical activity [42, 43] have had limited effects. The benefits of increasing childhood physical activity levels are likely to be particularly marked in the UK, where levels of overall physical activity in childhood are lower than in other European countries, as seen in the EYHS [8, 22, 28, 44, 45], and the prevalence of obesity and type 2 diabetes are high and increasing markedly [46, 47].

Conclusion Overall physical activity levels in children of different ethnic origin show consistent graded associations with adiposity and a wide range of cardiometabolic risk markers; the influence of physical activity on diabetes and CVD risk factors in childhood is substantially accounted for by adiposity measures. Modest increases in overall levels of physical activity could help to appreciably reduce adiposity and cardiometabolic risk.

Acknowledgements The work was supported by grants from the Wellcome Trust (068362/Z/02/Z), the British Heart Foundation (PG/ 06/003) and by the National Prevention Research Initiative (NPRI). The funding partners for this NPRI award were: British Heart 
Foundation; Cancer Research UK; Department of Health; Diabetes UK; Economic and Social Research Council; Medical Research Council; Research and Development Office for the Northern Ireland Health and Social Services; Chief Scientist Office, Scottish Executive Health Department; and Welsh Assembly Government. We are grateful to the members of the CHASE study team (J. Belbin, A. Brock, C. Brannagan, S. Holloway, C. McKay, M. McNamara, M. Price, R. Rafiq, C. Runeckles, L. Shepherd and A. Wathern) and to all participating schools, pupils and parents. We thank I. Gibb, S. Douglas and L. Cherry for laboratory analyses.

Duality of interest The authors declare that there is no duality of interest associated with this manuscript.

Open Access This article is distributed under the terms of the Creative Commons Attribution Noncommercial License which permits any noncommercial use, distribution, and reproduction in any medium, provided the original author(s) and source are credited

\section{References}

1. Nocon M, Hiemann T, Muller-Riemenschneider F, Thalau F, Roll S, Willich SN (2008) Association of physical activity with allcause and cardiovascular mortality: a systematic review and metaanalysis. Eur J Cardiovasc Prev Rehabil 15:239-246

2. Fogelholm M, Kukkonen-Harjula K (2000) Does physical activity prevent weight gain - a systematic review. Obes Rev 1:95-111

3. Li TY, Rana JS, Manson JE et al (2006) Obesity as compared with physical activity in predicting risk of coronary heart disease in women. Circulation 113:499-506

4. Hu FB, Stampfer MJ, Colditz GA et al (2000) Physical activity and risk of stroke in women. JAMA 283:2961-2967

5. Ku CY, Gower BA, Hunter GR, Goran MI (2000) Racial differences in insulin secretion and sensitivity in prepubertal children: role of physical fitness and physical activity. Obes Res 8:506-515

6. Leary SD, Ness AR, Smith GD et al (2008) Physical activity and blood pressure in childhood: findings from a population-based study. Hypertension 51:92-98

7. Ness AR, Leary SD, Mattocks C et al (2007) Objectively measured physical activity and fat mass in a large cohort of children. PLoS Med 4:e97

8. Sardinha LB, Andersen LB, Anderssen SA et al (2008) Objectively measured time spent sedentary is associated with insulin resistance independent of overall and central body fat in 9- to 10-year-old Portuguese children. Diabetes Care 31:569575

9. Wittmeier KD, Mollard RC, Kriellaars DJ (2008) Physical activity intensity and risk of overweight and adiposity in children. Obesity (Silver Spring) 16:415-420

10. Ekelund U, Sardinha LB, Anderssen SA et al (2004) Associations between objectively assessed physical activity and indicators of body fatness in 9- to 10-y-old European children: a populationbased study from 4 distinct regions in Europe (the European Youth Heart Study). Am J Clin Nutr 80:584-590

11. Gidding SS, Barton BA, Dorgan JA et al (2006) Higher selfreported physical activity is associated with lower systolic blood pressure: the Dietary Intervention Study in Childhood (DISC). Pediatrics 118:2388-2393

12. Schmitz KH, Jacobs DR Jr, Hong CP, Steinberger J, Moran A, Sinaiko AR (2002) Association of physical activity with insulin sensitivity in children. Int J Obes Relat Metab Disord 26:1310 1316
13. Sallis JF, Buono MJ, Freedson PS (1991) Bias in estimating caloric expenditure from physical activity in children. Implications for epidemiological studies. Sports Med 11:203-209

14. Ekelund U, Brage S, Froberg K et al (2006) TV viewing and physical activity are independently associated with metabolic risk in children: the European Youth Heart Study. PLoS Med 3:e488

15. Jimenez-Pavon D, Kelly J, Reilly JJ (2010) Associations between objectively measured habitual physical activity and adiposity in children and adolescents: systematic review. Int J Pediatr Obes 5:3-18

16. Wild SH, Fischbacher C, Brock A, Griffiths C, Bhopal R (2007) Mortality from all causes and circulatory disease by country of birth in England and Wales 2001-2003. J Public Health (Oxf) 29:191-198

17. Sproston K, Mindell J (2006) Health Survey for England 2004: Volume 1 . The health of minority ethnic groups. Stationery Office, London

18. Chan JC, Malik V, Jia W et al (2009) Diabetes in Asia: epidemiology, risk factors, and pathophysiology. JAMA 301:2129-2140

19. Danesh J, Wheeler JG, Hirschfield GM et al (2004) C-reactive protein and other circulating markers of inflammation in the prediction of coronary heart disease. N Engl J Med 350:13871397

20. Sattar N, Wannamethee SG, Forouhi NG (2008) Novel biochemical risk factors for type 2 diabetes: pathogenic insights or prediction possibilities? Diabetologia 51:926-940

21. Whincup PH, Nightingale CM, Owen CG et al (2010) Early emergence of ethnic differences in type 2 diabetes precursors in the UK: the Child Heart And health Study in England (CHASE Study). PLoS Med 7:e1000263. doi:10.1371/journal. pmed. 1000263

22. Owen CG, Nightingale CM, Rudnicka AR, Cook DG, Ekelund U, Whincup PH (2009) Ethnic and gender differences in physical activity levels among 9-10-year-old children of white European, South Asian and African-Caribbean origin: the Child Heart Health Study in England (CHASE Study). Int J Epidemiol 38:1082-1093

23. Andersen L, Dinesen B, Jorgensen PN, Poulsen F, Roder ME (1993) Enzyme immunoassay for intact human insulin in serum or plasma. Clin Chem 39:578-582

24. Levy JC, Matthews DR, Hermans MP (1998) Correct homeostasis model assessment (HOMA) evaluation uses the computer program. Diabetes Care 21:2191-2192

25. Office for National Statistics (2000) Standard Occupational Classification 2000. Office for National Statistics. Available from www.ons.gov.uk/about-statistics/classifications/current/SOC2000/ index.html, accessed 7 September 2009

26. Carroll RJ, Ruppert D, Stefanski LA, Crainiceanu CM (2006) Measurement error in nonlinear models: a modern perspective, 2nd edn. Chapman and Hall, Boca Raton

27. Andersen LB, Harro M, Sardinha LB et al (2006) Physical activity and clustered cardiovascular risk in children: a crosssectional study (The European Youth Heart Study). Lancet 368:299-304

28. Ortega FB, Ruiz JR, Sjostrom M (2007) Physical activity, overweight and central adiposity in Swedish children and adolescents: the European Youth Heart Study. Int J Behav Nutr Phys Act 4:61

29. Brage S, Wedderkopp N, Ekelund U et al (2004) Objectively measured physical activity correlates with indices of insulin resistance in Danish children. The European Youth Heart Study (EYHS). Int J Obes Relat Metab Disord 28:1503-1508

30. Cook DG, Mendall MA, Whincup PH et al (2000) C-reactive protein concentration in children: relationship to adiposity and other cardiovascular risk factors. Atherosclerosis 149:139-150

31. Thomas NE, Baker JS, Graham MR, Cooper SM, Davies B (2008) C-reactive protein in schoolchildren and its relation to 
adiposity, physical activity, aerobic fitness and habitual diet. Br J Sports Med 42:357-360

32. Ruiz JR, Ortega FB, Warnberg J, Sjostrom M (2007) Associations of low-grade inflammation with physical activity, fitness and fatness in prepubertal children; the European Youth Heart Study. Int J Obes (Lond) 31:1545-1551

33. No authors listed (2009) December 15, 2009: Endocrinologic and Metabolic Drugs Advisory Committee Meeting Announcement. Available from www.fda.gov/AdvisoryCommittees/Calendar/ ucm187991.htm, accessed 11 January 2010

34. Ekelund U, Sjostrom M, Yngve A, Poortvliet E, Nilsson A, Froberg $\mathrm{K}$ et al (2001) Physical activity assessed by activity monitor and doubly labeled water in children. Med Sci Sports Exerc 33:275-281

35. Nyberg G, Ekelund U, Marcus C (2009) Physical activity in children measured by accelerometry: stability over time. Scand J Med Sci Sports 19:30-35

36. Riddoch CJ, Leary SD, Ness AR et al (2009) Prospective associations between objective measures of physical activity and fat mass in 12-14 year old children: the Avon Longitudinal Study of Parents and Children (ALSPAC). BMJ 339:b4544

37. Gillies CL, Abrams KR, Lambert PC et al (2007) Pharmacological and lifestyle interventions to prevent or delay type 2 diabetes in people with impaired glucose tolerance: systematic review and meta-analysis. BMJ 334:299

38. Reilly JJ, Methven E, McDowell ZC et al (2003) Health consequences of obesity. Arch Dis Child 88:748-752

39. Srinivasan SR, Myers L, Berenson GS (2002) Predictability of childhood adiposity and insulin for developing insulin resistance syndrome (syndrome $\mathrm{X}$ ) in young adulthood: the Bogalusa Heart Study. Diabetes 51:204-209
40. Ekelund U, Anderssen SA, Froberg K, Sardinha LB, Andersen LB, Brage S (2007) Independent associations of physical activity and cardiorespiratory fitness with metabolic risk factors in children: the European youth heart study. Diabetologia 50:18321840

41. Summerbell CD, Waters E, Edmunds L, Kelly SAM, Brown T, Campbell KJ (2005) Interventions for preventing obesity in children. Cochrane Database of Systematic Reviews, Issue 3. Art. No.: CD001871. doi:10.1002/14651858.CD001871.pub2

42. Reilly JJ, Kelly L, Montgomery C, Williamson A, Fisher A, McColl JH et al (2006) Physical activity to prevent obesity in young children: cluster randomised controlled trial. BMJ 333:1041

43. Nader PR, Stone EJ, Lytle LA et al (1999) Three-year maintenance of improved diet and physical activity: the CATCH cohort. Child and Adolescent Trial for Cardiovascular Health. Arch Pediatr Adolesc Med 153:695-704

44. Riddoch CJ, Andersen LB, Wedderkopp N et al (2004) Physical activity levels and patterns of 9- and 15-yr-old European children. Med Sci Sports Exerc 36:86-92

45. Riddoch CJ, Mattocks C, Deere K et al (2007) Objective measurement of levels and patterns of physical activity. Arch Dis Child 92:963-969

46. Stamatakis E, Primatesta P, Chinn S, Rona R, Falascheti E (2005) Overweight and obesity trends from 1974 to 2003 in English children: what is the role of socioeconomic factors? Arch Dis Child 90:999-1004

47. Haines L, Wan KC, Lynn R, Barrett TG, Shield JP (2007) Rising incidence of type 2 diabetes in children in the U.K. Diabetes Care 30:1097-1101 